\section{Diferenciación del complejo Entamoeba histolytica/Entamoeba dispar mediante Gal/GalNAc-lectina y PCR en aislamientos colombianos}

\author{
OMAIRA Y. LÓPEZ2,a, MYRIAM C. LÓPEZ ${ }^{2, a}$, VLADIMIR CORREDOR ${ }^{2, b}$, \\ M. CLARA ECHEVERRI ${ }^{2}$, ANÁLIDA E. PINILLA ${ }^{1, c}$
}

Medicina Interna.

2 Departamento de

Salud Pública.

Facultad de Medicina,

Universidad Nacional de

Colombia.

aBacterióloga.

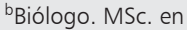
Educación.

Fuente de apoyo

financiero: Código 5443

División Investigación

Sede Bogotá. Universidad

Nacional de Colombia.

Recibido el 3 de junio de

2011, aceptado el 21 de

diciembre de 2011.

Correspondencia a:

Análida Elizabeth Pinilla

Roa. MD. I. Departamento

de Medicina Interna.

Facultad de Medicina.

Universidad Nacional de

Colombia.

Carrera 45 No 26-85 -

Edificio Uriel Gutiérrez.

Bogotá D.C. - Colombia.

Facultad de Medicina.

Bogotá, Colombia.

Telefax (57-1) 3165000

extensión 15167/15033.

aepinillar@unal.edu.co
Background: Entamoeba histolytica and Entamoeba dispar are morphologically identical. However, the former is highly pathogenic and the latter is not. Aim: To differentiate Entamoeba histolytica from Entamoeba dispar through ELISA and PCR techniques in Colombian isolates from feces. Material and Methods: Descriptive study of Colombian fecal samples from 53 males and 47 women, that were positive for the complex E. histolytica/E. dispar on light microscopy. Positive samples were cultured on Robinson medium to isolate trophozoites. The presence of specific Gall GalNAc-lectin was determined by ELISA and polymerase chain reaction in genomic DNA, using the combination of three nucleotides that recognize a variable region of $16 S$ small subunit ribosomal RNA, generating a 166 base pair (bp) product for $E$. histolytica and $752 \mathrm{pb}$ product for E. dispar. Results: After verification, only eight of the 100 samples were positive for the complex E. histolytica/E. dispar and were cultivated. Isolates were obtained in six cultures, one corresponded to E. histolytica and six to E. dispar. Conclusions: The presence of E. histolytica/E. dispar complex was largely overestimated with light microscopy. In the few samples where isolates were obtained, the technique described differentiated between both strains.

(Rev Med Chile 2012; 140: 476-483).

Key words: Dhg12; Entamoeba dispar; Entamoeba histolytica; Galectins.
L

a disentería amebiana y sus complicaciones es causada por el protozoo Entamoeba hisestimaba en 500 millones las personas infectadas en el mundo. Estudios bioquímicos, inmunológicos y genómicos confirmaron la hipótesis de Brumpt sobre la existencia de dos especies, una patógena y otra no patógena, morfológicamente idénticas, constituyendo un complejo -Entamoeba histolytica/Entamoeba dispar-, diferenciables sólo mediante patrones isoenzimáticos, la presencia o ausencia de adhesina, o mediante técnicas moleculares ${ }^{1-4}$.
En la amebiasis intestinal, el diagnóstico habitual de laboratorio se fundamenta en el estudio microscópico de la materia fecal, el cual tiene la gran limitación de no permitir hacer la diferencia entre E. histolytica, E. dispar, E. moshkovskii pero si con E. hartmanni por tamaño. La detección de la lectina de galactosa y $\mathrm{N}$ acetil galactosamina (Gal/ GalNAc-lectina) en materia fecal mediante la técnica de ELISA y la amplificación por PCR de fragmentos específicos de $\mathrm{ADN}$ genómico sí permiten identificar las especies del complejo, siendo técnicas de elección para el diagnóstico diferencial de estas especies ${ }^{5-7}$. 
En Colombia, la encuesta de morbilidad de1980 informó una prevalencia para E. histolytica de $12,1 \%{ }^{8}$. Años más tarde, la OMS (1997) reglamentó reportar en materia fecal el complejo E. histolytica/E. dispar. Por esto, se realizaron estudios puntuales para diferenciar estas dos especies mediante ELISA para la detección de la Gal/ GalNAc-lectina en materia fecal; las frecuencias relativas comunicadas, fueron de $0,6-1,4 \%$ para E. histolytica y de $15-17 \%$ para E. dispar ${ }^{9,10}$. En otros países, como Venezuela, mediante PCR se informó una prevalencia para E. histolytica $6,31 \%$ y para E. dispar $4,44 \%{ }^{11}$; en Nicaragua reportaron para E. histolytica $1,5 \%$ y para E. dispar $7,5 \%{ }^{12}$ y en México se reportaron las siguientes prevalencias E. histolytica de $11,4 \%$ y para E. dispar $7,2 \%$ y con ambas especies del $2,4 \%{ }^{13}$.

El objetivo del presente trabajo fue diferenciar las especies E. histolytica y E. dispar mediante las pruebas de ELISA y PCR en muestras de materia fecal de pacientes, de diferentes ciudades de Colombia, y a quienes se les había diagnosticado por microscopía de luz la presencia de quistes del complejo E. histolytica/E. dispar; no se tuvo en cuenta la historia clínica. La aplicación de estas técnicas en el diagnóstico de la amebiasis, podrá ser la base para estudios epidemiológicos que permitan determinar la prevalencia real de la infección por E. histolytica.

\section{Materiales y Métodos}

Se realizó un estudio descriptivo entre julio de 2007 y abril de 2008, en la medida que las muestras eran remitidas al centro de referencia de parasitología, procedentes de diferentes laboratorios con diagnóstico de quistes del complejo $E$. histolytica/E. dispar, mediante microscopia de luz. En el formato de remisión de la muestra, se registró género y procedencia, sin importar el motivo de consulta y la enfermedad actual.

Luego de verificar las muestras realmente positivas para el complejo E. histolytica/E. dispar en el centro de referencia (sólo 8/100), se cultivaron en medio de Robinson ${ }^{14}$ para lograr el aislamiento, recuperación y congelación de trofozoítos. A partir de éstos, se determinó la presencia de la Gal/GalNAc-lectina específica mediante ELISA utilizando el kit Techlab E. histolytica II test ${ }^{\circledR}$ de segunda generación ${ }^{15}$.

\section{Reacción en cadena de polimerasa (PCR), muestras y controles}

Para la PCR, el ADN de los trofozoítos concentrados y congelados fue extraído siguiendo la técnica de fenol/cloroformo/alcohol isoamílico (PCI $25: 24: 1)$ y almacenados a $-20^{\circ} \mathrm{C}$ hasta su uso ${ }^{16}$. Los trofozoítos fueron congelados inicialmente en nitrógeno líquido a $-196^{\circ} \mathrm{C}$ y llevados posteriormente a $-20^{\circ} \mathrm{C}$. Los controles positivos utilizados para la realización del PCR, correspondieron a ADN obtenido a partir de cultivos axénicos en medio TYS-33 de E. histolytica HM1: ISS; el ADN de E. dispar SAW760 fue proporcionado por el Dr. Graham Clark del London School of Hygiene and Tropical Medicine. Como control negativo se utilizó ADN proveniente de una muestra de materia fecal de un individuo sano, que fue negativo por diagnóstico parasitológico de microscopía de luz y por ELISA ${ }^{15}$. Los controles negativo y positivo de E. histolytica HM1: ISS también fueron congelados inicialmente en nitrógeno líquido a $-196^{\circ} \mathrm{C}$ y llevados posteriormente a $-20^{\circ} \mathrm{C}$.

Los tres oligonucleótidos empleados en PCR fueron descritos por Hamzah et $\mathrm{al}^{16}$. La mezcla de los tres oligonucleótidos permite la amplificación específica de ADN genómico de E. histolytica y E. dispar. La secuencia del oligonucleótido sentido (EntaF) representa la región central del gen que codifica para la subunidad pequeña del ARN ribosomal, conservada en ambas especies de Entamoeba; los oligonucleótidos antisentido EhR y EdR, específicos para E. histolytica y E. dispar respectivamente, representan secuencias variables del mismo gen. Las siguientes fueron las secuencias: EntaF: 5'-ATG CAC GAG AGC GAA AGC AT-3'; EhR: 5'-GAT CTA GAA ACA ATG CTT CTC T-3'; $E d R:$ 5'-CAC CAC TTA CTA TCC CTA CC-3'. La combinación de oligonucleótidos en una misma mezcla de reacción generó de manera específica, productos de $166 \mathrm{pb}$ para el ADN de E. histolytica y de $752 \mathrm{pb}$ para el ADN de E. dispar ${ }^{17}$.

\section{Amplificación por PCR y diferenciación de especies}

La mezcla de reacción se realizó con $1,25 \mu \mathrm{M}$ de cada deoxinucleótido trifosfato (dNTPs), $0,2 \mu \mathrm{M}$ de cada oligonucleótido (sentido y antisentido), $6 \mathrm{mM}$ de $\mathrm{MgCl}_{2}, 0,05 \mathrm{U} / \mu \mathrm{l}$ de Taq polimerasa, $1 \mathrm{X}$ de Taq buffer, y $4 \mu \mathrm{l}$ del ADN extraído, para un volumen final de $20 \mu \mathrm{l}$ de mezcla de reacción. La amplificación de los fragmentos de ADN espe- 
cíficos de cada especie se inició con una primera desnaturalización a $94^{\circ} \mathrm{C}$ durante 5 minutos, seguida de 30 ciclos a $94^{\circ} \mathrm{C}$ durante 1 minuto, $58^{\circ} \mathrm{C}$ durante 1 minuto, $72^{\circ} \mathrm{C}$ durante 1 minuto, y una extensión final a $72^{\circ} \mathrm{C}$ durante 10 minutos. Los productos de amplificación se visualizaron mediante electroforesis en geles de agarosa al 1,5\% teñidos con bromuro de etidio ${ }^{16,17}$.

\section{Determinación de sensibilidad y especificidad de oligonucleótidos}

Para determinar la sensibilidad de los oligonucleótidos, diferentes concentraciones del ADN de E. histolytica HM1:ISS y E. dispar SAW760 fueron preparadas mediante diluciones seriadas 1:10, obteniendo amplificación desde $4 \mathrm{ng}$ hasta 0,02 pg de ADN de E. dispar y desde $14 \mathrm{ng}$ hasta $0,01 \mathrm{pg}$ del ADN de E. histolytica. La combinación de los ADN de las cepas control fue probada en PCR para eliminar la posibilidad de amplificación cruzada, utilizando los dos oligonucleótidos especie-específicos y la combinación de los tres oligonucleótidos en la misma mezcla de reacción.

Adicionalmente, la especificidad de los oligonucleótidos fue confirmada mediante amplificación de $\mathrm{ADN}$ de diferentes bacterias patógenas involucradas en procesos diarreicos (Salmonella sp., Escherichia coli, Staphylococcus aureus), Blastocystis hominis, Entamoeba invadens y ADN humano con los tres oligonucleótidos en una misma mezcla de reacción.

\section{Aspectos éticos}

Se cumplieron las normas éticas para investigación en salud vigentes en Colombia y fue aprobado por el Comité de Ética de la Facultad de Medicina de la Universidad Nacional de Colombia ${ }^{18}$.

\section{Resultados}

El estudio se efectuó entre julio de 2007 y abril de 2008, hasta alcanzar la meta proyectada de 100 muestras con diagnóstico de quistes del complejo E. histolytica/E. dispar por microscopia de luz, realizada en la institución de origen. El total de muestra correspondió a 53 hombres y 47 mujeres; procedentes de Bogotá y de otros departamentos (Boyacá, Cauca, Huila, Meta, Putumayo y Tolima).

Se procedió a verificar el diagnóstico microscópico y se encontró que solamente 8/100 eran positivas para quistes del complejo E. histolytica y E. dispar; también se visualizaron otros protozoarios y helmintos; además, $26 \%$ de las muestras tenían macrófagos (Tabla 1). Las 8 muestras con quistes fueron cultivadas en medio de Robinson, pero hubo aislamiento sólo en 6 casos y en los otras 2 no hubo progreso del cultivo. A partir de los cultivos con trofozoítos, se determinó la presencia de la Gal/GalNAc-lectina mediante ELISA y la amplificación específica de ADN genómico por PCR visibles en la electroforesis de agarosa, encontrándose sólo 1 cepa de E. histolytica y 5 cepas de E. dispar (Tabla 2, Figuras 1 y 2).

La utilización de los oligonucleótidos (EntaF/ ERh) generó productos de $166 \mathrm{pb}$ cuando se utilizó ADN de las cepas control HM1: ISS de E. histolytica como con los oligonucleótidos específicos (EntaF/ERd) para SAW 760 de E. dispar. Los productos generados fueron de $752 \mathrm{pb}$ demostrando que la mezcla de oligonucleótidos no produce amplificación cruzada entre las especies del complejo. Resultados similares se observaron con la combinación de los tres oligonucleótidos (EntaF/ERh/ERd), en la misma mezcla de reacción usando ADN de las cepas control. En todas las combinaciones, fue posible observar intensidades similares de los fragmentos amplificados y no se observó amplificación cruzada al utilizar la mezcla

Tabla 1. Hallazgos en materia fecal por microscopia de luz en el centro de referencia

\begin{tabular}{|lcc|}
\hline Agente & $\begin{array}{c}\text { Frecuencia } \\
\mathbf{( \% )}\end{array}$ & $\begin{array}{c}\text { Intervalo de } \\
\text { confianza } \\
\text { IC 95\% }\end{array}$ \\
\hline Entamoeba coli & $31 / 100(31)$ & $21,1-44$ \\
\hline Endolimax nana & $25 / 100(25)$ & $16,2-37$ \\
\hline Giardia duodenalis & $16 / 100(16)$ & $9,1-26$ \\
\hline Blastocystis hominis & $15 / 100(15)$ & $8,4-24,7$ \\
\hline $\begin{array}{l}\text { Complejo } \\
\text { E. histolytica/E. dispar }\end{array}$ & $8 / 100(8)$ & $3,5-15,8$ \\
\hline lodamoeba bütschlii & $7 / 100(7)$ & $2,8-14,4$ \\
\hline Chilomastix mesnilii & $5 / 100(5)$ & $1,6-11,7$ \\
\hline Entamoeba hartmanni & $4 / 100(4)$ & $1,1-10,2$ \\
\hline Áscaris lumbricoides & $1 / 100(1)$ & $0-0,6$ \\
\hline Strongyloides stercolaris & $1 / 100(1)$ & $0-0,6$ \\
\hline Hymenolepis nana & $1 / 100(1)$ & $0-0,6$ \\
\hline
\end{tabular}


Tabla 2. Resultados en las muestras positivas para el complejo E. histolytica/E. dispar

\begin{tabular}{|cccccc|}
\hline $\begin{array}{c}\text { Identificación } \\
\text { de la muestra }\end{array}$ & $\begin{array}{c}\text { Resultado } \\
\text { microscópico } \\
\text { (quistes) }\end{array}$ & $\begin{array}{c}\text { Aislamiento } \\
\text { en cultivo }\end{array}$ & $\begin{array}{c}\text { Gal/GalNAc lectina } \\
\text { específica (ELISA) }\end{array}$ & E. histolytica & E. dispar \\
\hline 1 & Positivo & Positivo & Negativo & Negativo & Positivo \\
\hline 2 & Positivo & Positivo & Negativo & Negativo & Positivo \\
\hline 3 & Positivo & Positivo & Negativo & Negativo & Positivo \\
\hline 4 & Positivo & Positivo & Negativo & Negativo & Positivo \\
\hline 5 & Positivo & Positivo & Negativo & Negativo & Positivo \\
\hline 6 & Positivo & Positivo & Positiva & Positiva & Negativo \\
\hline 7 & Positivo & Negativo & NA & NA & NA \\
\hline 8 & Positivo & Negativo & NA & NA & NA \\
\hline
\end{tabular}

NA: no aplica.

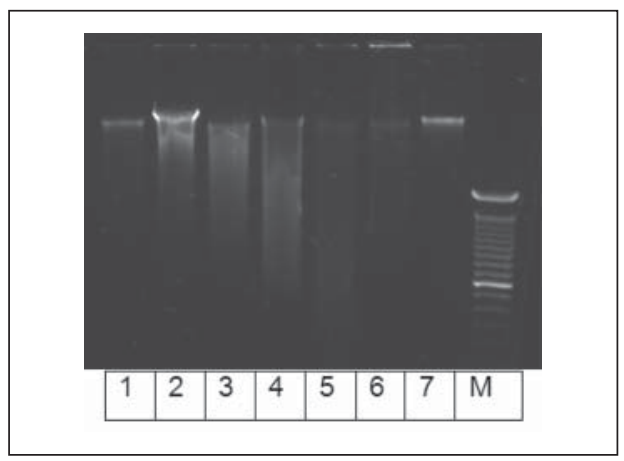

Figura 1. Extracciones $A D N$ genómico de aislamientos colombianos. Carril 1, ADN aislamiento 1 E. dispar; carril 2, ADN aislamiento 2 E. dispar; carril 3, ADN aislamiento 3 E. dispar; carril 4, ADN aislamiento 4 E. dispar; carril 5, ADN aislamiento 5 E. dispar; carril 6, ADN aislamiento colombiano E. histolytica; carril 7, ADN humano (control positivo de ADN genómico); M, marcador de peso molecular de 100 pb.
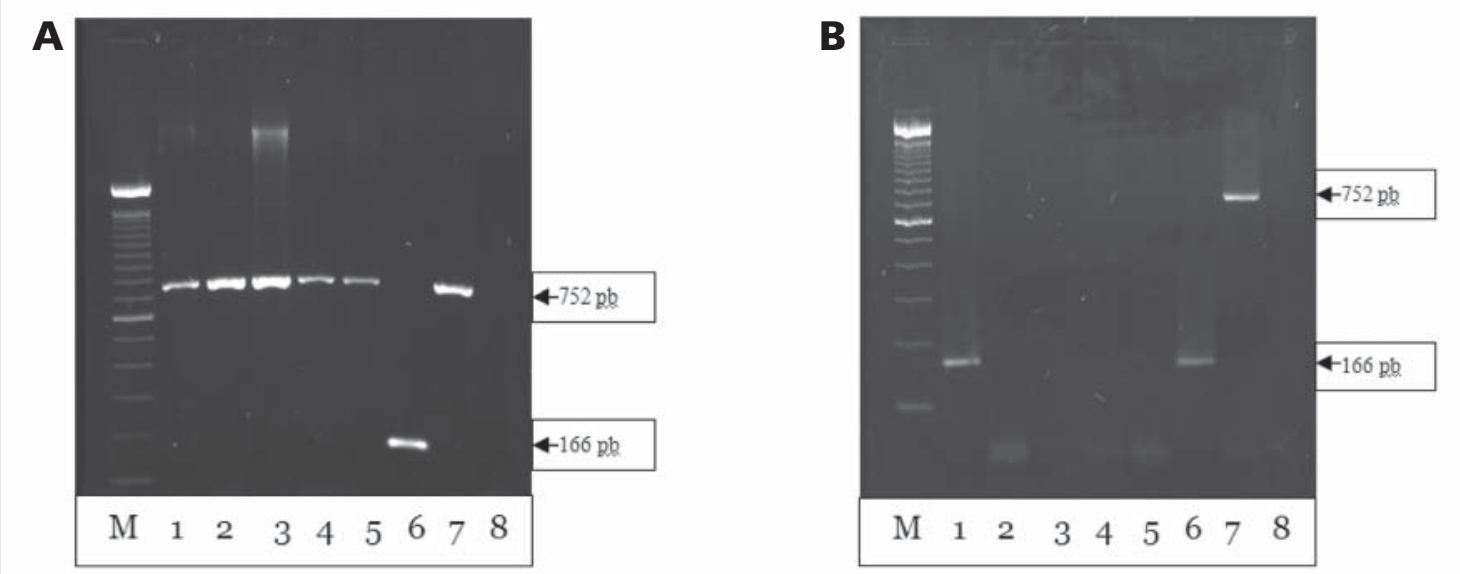

Figura 2. (A) Especificidad de las reacciones con los oligonucleótidos EntaF/ERd y EntaF/ERh en la diferenciación de especies del complejo. M, marcador de peso molecular escalera de $100 \mathrm{pb}$; carril 1, ADN aislamiento 1 E. dispar; carril 2, ADN aislamiento 2 E. dispar; carril 3, ADN aislamiento 3 E. dispar; carril 4, ADN aislamiento 4 E. dispar; carril 5, ADN aislamiento 5 E. dispar; carril 6, ADN HM1: ISS (control positivo); carril 7, ADN E. dispar SAW 760 (control positivo); carril 8, agua (control negativo). (B). Especificidad de oligonucleótidos EntaF/ERd/ERh usando ADN de varios organismos. M, marcador de peso molecular, escalera de 100 pb; carril 1, ADN aislamiento colombiano E. histolytica; carril 2, ADN Salmonella sp; carril 3, ADN humano; carril 4, ADN Blastocystis hominis; carril 5, ADN Entamoeba invadens; carril 6, ADN E. histolytica HM1: ISS (control positivo); carril 7, ADN E. dispar SAW 760 (control positivo); carril 8, agua (control negativo). 


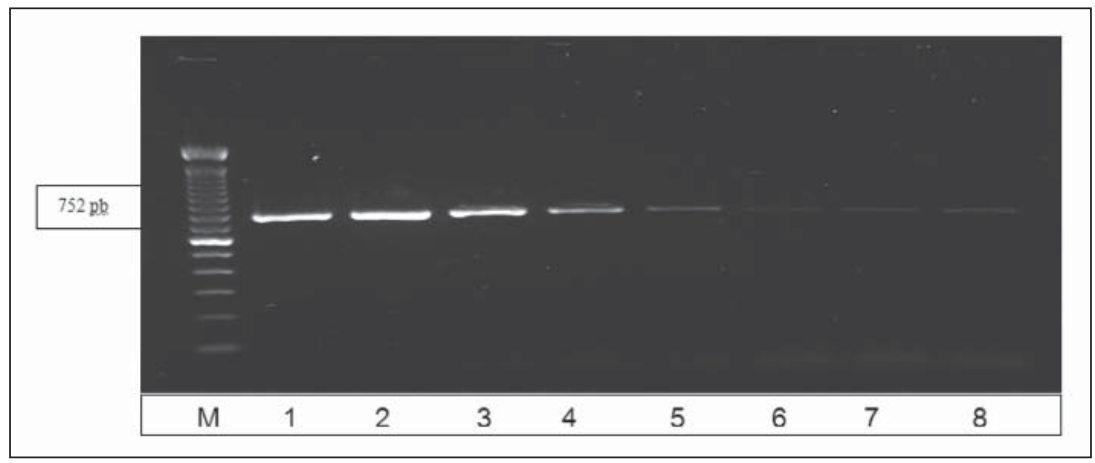

Figura 3. Sensibilidad de la reacción de PCR. Amplificación utilizando los oligonucleótidos EntaF/ERd y ADN control de $E$. dispar SAW760. M, marcador de peso molecular de 100 pb; carril 1, dilución ADN 1:101; carril 2, dilución ADN 1:10²; carril

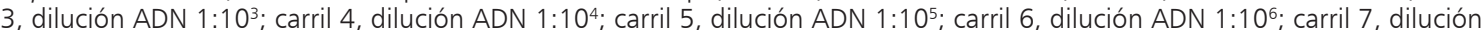
ADN 1:107; carril 8, dilución ADN 1:108.

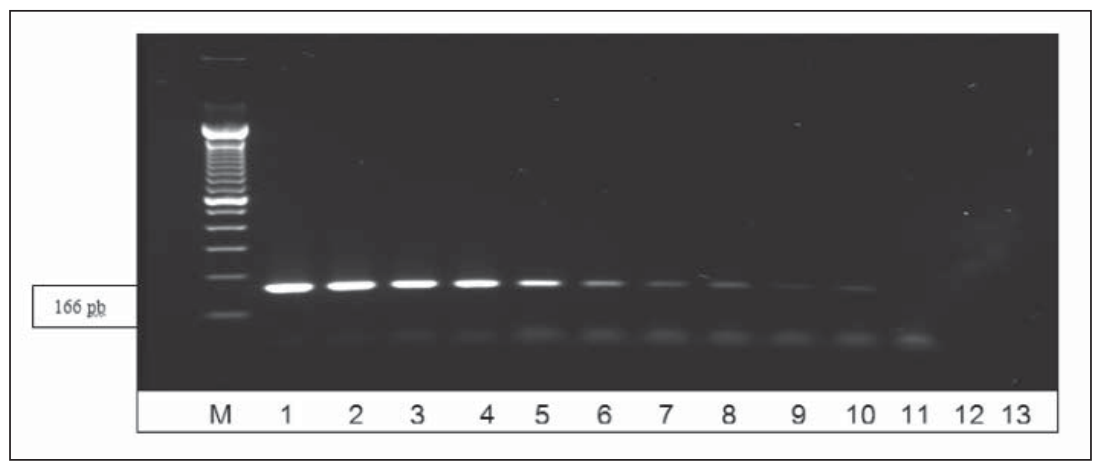

Figura 4. Sensibilidad de la reacción de PCR. Amplificación utilizando los oligonucleótidos EntaF/ERh y ADN control de $E$. histolytica HM1: ISS. M, marcador de peso molecular de 100 pb; carril 1, dilución ADN 1:10; carril 2, dilución ADN 1:10²; carril 3, dilución $A D N ~ 1: 10^{3}$; carril 4, dilución ADN 1:104; carril 5, dilución ADN 1:105; carril 6, dilución ADN 1:106; carril 7, dilución

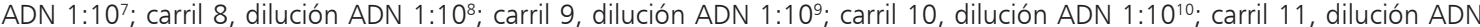
$1: 10^{11}$; carril 12 , dilución $1: 10^{12}$; carril 13 , agua (control negativo).

de los tres oligonucleótidos en presencia de ADN humano, bacteriano y proveniente de otros parásitos intestinales (Figuras 2A y 2B).

La sensibilidad de la reacción de amplificación fue evaluada mediante diluciones seriadas 1:10 del ADN de los controles positivos E. dispar SAW 760 y E. histolytica HM1: ISS. Los resultados obtenidos muestran niveles de detección de hasta 0,04 pg de $\mathrm{ADN}$ de E. dispar y 0,01pg de ADN de E. histolytica (Figuras 3 y 4 ).

\section{Discusión}

El examen directo, por microscopia de luz con solución salina y lugol, ha sido de primera línea para la visualización tanto de trofozoítos como quistes del complejo E. histolytica/E. dispar; sin embargo, se requiere de experiencia y entrenamiento del profesional. Además, existe dificultad para diferenciar al microscopio de luz entre un quiste y un leucocito o entre los quistes de otras amebas (E. moshkovskii, E. coli y E. hartmanni). El diagnóstico etiológico de la amebiasis intestinal no es posible con microscopia de luz debido a que las dos especies del complejo tienen características morfológicas idénticas y no se pueden distinguir la E. histolytica de la E. dispar, por tanto, se requiere de pruebas bioquímicas, inmunológicas y moleculares para confirmar la especie ${ }^{19-21}$.

En los pacientes con historia clínica sugestiva de patología invasiva por E. histolytica y evidencia de trofozoítos hematófagos, es necesario iniciar tratamiento empírico ${ }^{2,20}$. 
En este estudio, los hallazgos al microscopio de luz realizados en las instituciones de origen, fueron revisados en el centro de referencia; de las 100 muestras de materia fecal, sólo se verificó el hallazgo del complejo E. histolytica/E. dispar en 8\% y $92 \%$ restante eran falsos positivos; en cuanto al género, no se encontró diferencia significativa; se evidenció E. hartmanni en 4\%, destacando que esta ameba puede diferenciarse del complejo sólo por el tamaño, por esta razón los quistes observados deben medirse. En este estudio, el sobrediagnóstico se explica por las limitaciones técnicas de la microscopía de luz con sensibilidad menor de 60\% y especificidad entre 10 y $50 \%$ para determinar el complejo E. histolytica/E. dispar; lo anterior, lleva a un diagnóstico equívoco de amebiasis intestinal y prescripción innecesaria de antiamebianos de acción tisular, por lo que se recomienda al médico correlacionar las manifestaciones clínicas y los aspectos epidemiológicos con los resultados del coprológico ${ }^{3}$. De otra parte, el hallazgo de otros protozoarios y helmintos patógenos, está acorde con la prevalencia de parasitosis en países tropicales como Colombia ${ }^{8}$.

El cultivo no es una prueba de rutina para uso clínico, pero dada su alta especificidad, es prueba de oro para el aislamiento y así realizar las pruebas moleculares como PCR y la Gal/GalNAc-lectina específica para la diferenciación de las especies del complejo ${ }^{3,16}$.

En este estudio, la detección de Gal/GalNAclectina específica mediante ELISA, mostró una frecuencia de $1 \%$ para E. histolytica, semejante a la prevalencia informada en Colombia, entre 0,6$1,4 \%{ }^{9,10}$ y similar a la informada por Leiva et al en Nicaragua, de $1,5 \%{ }^{12}$, a diferencia de lo hallado en Venezuela y México sin tenar una explicación evidente ${ }^{11-13}$; sin embargo, la prevalencia encontrada en otras regiones del mundo es hasta $21 \%{ }^{22-24}$.

Para E. dispar, la frecuencia en este estudio fue $5 \%$ en comparación a la prevalencia informada en Colombia en estudios previos (15-17\%), análogo con otros estudios en Latinoamérica. No obstante, en otros lugares del mundo se ha encontrado hasta $24 \%$ de prevalencia para E. dispar ${ }^{9-13,22-24}$.

Puesto que este trabajo no fue un estudio probabilístico, las frecuencias encontradas aportan información que debe ser cotejada con futuros estudios de prevalencia, con una selección aleatoria de la muestra. Por ahora, se puede inferir que estudios previos sin esta tecnología, informaban frecuencias más altas de E. histolytica porque se incluía la E. dispar ${ }^{8}$.

Con el fin de evitar la presencia de inhibidores de la PCR presentes en la materia fecal, la extracción se realizó a partir de trofozoítos aislados en el cultivo. Se precisa que en otros estudios, se ha demostrado que la extracción manual, degrada parcialmente el ADN para la PCR. Por ello, se recomienda utilizar un kit de extracción para facilitar el proceso, independiente al tipo de muestra a analizar, incluso en materia fecal ${ }^{7,17,24-30}$. Se adaptó una reacción de PCR que permite la diferenciación de E. histolytica y E. dispar, mediante la utilización de tres oligonucleótidos especie-específicos y no se observó amplificación cruzada al utilizar la mezcla de los tres oligonucleótidos, en presencia de ADN humano, bacteriano o proveniente de otros parásitos intestinales.

Los resultados obtenidos muestran que la PCR es capaz de detectar hasta 0,04 pg del ADN de $E$. dispar y $0,01 \mathrm{pg}$ de $\mathrm{ADN}$ de E. histolytica, lo que demuestra que los oligonucleótidos son altamente sensibles para la diferenciación de las especies del complejo en ADN extraído de parásitos cultivados. En los ensayos de sensibilidad, se mantienen adecuados límites de detección, si se tiene en cuenta que el peso molecular de un genoma de $E$. histolytica por célula es de 0,02 pg. Según el límite de detección determinado en este estudio $(0,01$ pg), con los oligonucleótidos específicos para $E$. histolytica, sería posible amplificar ADN a partir de un trofozoíto o quiste y con los oligonucleótidos para E. dispar, a partir de dos trofozoítos o quistes presentes en la muestra de interés ${ }^{7,17,24}$.

El protocolo de extracción y amplificación y las concentraciones de reactivos utilizados para la mezcla de la PCR, deben ser ensayados con ADN extraído con kit a partir de trofozoítos congelados y criopreservados, muestras de materia fecal, biopsias y aspirado de absceso hepático amebiano con el fin de adaptar y estandarizar las condiciones en cada situación específica.

En resumen, estas dos técnicas son útiles para precisar la prevalencia real de E. histolytica en estudios epidemiológicos en Colombia, dado que en la actualidad hay sobre diagnóstico de infección amebiana por la imposibilidad de diferenciar las dos especies del complejo E. histolytica/E. dispar y otras amebas en materia fecal ${ }^{16,31}$; pero, la prueba Techlab E. histolytica II test ${ }^{\circledR}$ de segunda generación para Gal/GalNAc-lectina específica, 
empleada no está disponible en Colombia, por ser una prueba de alto costo para el Sistema General de Seguridad Social en Salud. Finalmente, el diagnóstico de la amebiasis se hace más complejo, sin las técnicas moleculares, para discernir como causante la E. histolytica, porque estudios recientes han informado la E. moshkovskii y está en estudio su patogenicidad y epidemiología $a^{32,33}$.

Agradecimientos: A los Doctores: Graham Clark del London School of Hygiene and Tropical Medicine; Dan Eichinger de New York University; la Universidad Nacional de Colombia, División Investigación Sede Bogotá, código 5443 y los profesores Angélica Knudson, Hernando del Castillo y Daniel Velandia de la Universidad Nacional de Colombia.

\section{Referencias}

1. Diamond LS, Clark CG. A redescription of Entamoeba histolytica Schaudinn, 1903 (Emended Walker, 1911) separating it from Entamoeba dispar Brumpt, 1925. J Eukaryot Microbiol 1993; 40: 340-4.

2. WHO/PAHO/UNESCO report. A consultation with experts on amoebiasis. Mexico city, Mexico 28-29 January 1997. Epidemiol Bull 1997; 18: 13-4.

3. Tanyuksel M, Petri WA Jr. Laboratory Diagnosis of Amebiasis. Clin Microbiol Rev 2003; 16: 713-29.

4. Sargeaunt PG, Williams JE. The differentiation of invasive and noninvasive Entamoeba histolytica by isoenzyme electrophoresis. Trans R Soc Trop Med Hyg 1978; 72: 519-21.

5. Haque R, Petri WA Jr. Diagnosis of amebiasis in Bangladesh. Arch Med Res 2006; 37: 273-6.

6. Haque R, Huston CD, Hughes M, Houpt E, Petri WA Jr. Amebiasis. N Engl J Med 2003; 348: 1565-73.

7. Verweij JJ, Blotkamp J, Brienen E, Aguirre A, Polderman A. Differentiation or Entamoeba histolytica and Entamoeba dispar cysts using Polymerase Chain Reaction on DNA isolated from faeces with spin columns. Eur J Clin Microbiol Infect Dis 2000; 19: 358-61.

8. Cáceres E, Castaño de Romero L, Estupiñán D, López MC, Páez S, Pinilla CA, et al. En: Corredor A, Arciniegas E, Hernández CA eds. Parasitismo intestinal. Ministerio de Salud, Instituto Nacional de Salud. Bogotá: Instituto Nacional de Salud 2000; 67-8.

9. Guzmán C, López MC, Reyes P, Gómez J, Corredor A, Agudelo CA. Diferenciación de Entamoeba histolytica y Entamoeba dispar en muestras de materia fecal por detección de adhesina de E. histolytica mediante ELISA. Biomédica 2001; 21: 167-71.

10. Gallego M, Gómez JE, Torres E, Lora F. Prevalencia de E. histolytica en asentamientos temporales posterremoto de la ciudad de Armenia. Infectio 2003; 7: 190-4.

11. Mora L, García A, De Donato M, Urdaneta H. Epidemiologic and molecular study of Entamoeba histolytica and Entamoeba dispar strains in pacients with diarrhea in Cumana, Sucre state, Venezuela]. Invest Clin 2008; 49: 225-37.

12. Leiva B, Lebbad M, Winiecka-Krusnell J, Altamirano I, Tellez A, Linder E Overdiagnosis of Entamoeba histolytica and Entamoeba dispar in Nicaragua: a microscopic, triage parasite panel and PCR study. Arch Med Res 2006; 37: 529-34.

13. Ramos F, Morán P, González E, García G, Ramiro M, Gómez A, et al. Entamoeba histolytica and Entamoeba dispar: prevalence infection in a rural Mexican community. Exp Parasitol 2005; 110: 327-30.

14. Robinson GL. The Laboratory Diagnosis of Human Parasitic Amoebae. Trans R Soc Trop Med Hyg 1968; 62: 285-94.

15. Haque R, Mollah NU, Ali IK, Alam K, Eubanks A, Lyerly $\mathrm{D}$, et al. Diagnosis of amebic liver abscess and intestinal infection with the TechLab Entamoeba histolytica II antigen detection and antibody tests. J Clin Microbiol 2000; 38: 3235-9.

16. Hamzah Z, Petmitr S, Mungthin M, Leelayoova S, Chavalitshewinkoon-Petmir P. Differential detection of Entamoeba histolytica, Entamoeba dispar, and Entamoeba moshkovskii by single -round PCR assay. J Clin Microbiol 2006; 44: 3196-3200.

17. Acuña-Soto R, Samuelson J, De Girolami P, Zárate L, Millan-Velasco F, Schoolmick G. Application of the polymerase chain reaction to the epidemiology of pathogenic and non-pathogenic Entamoeba histolytica. Am J Trop Med and Hyg 1993; 48: 58-70.

18. Ministerio de Salud. Dirección de desarrollo científico y tecnológico. Normas científicas, técnicas y administrativas para la investigación en salud. Resolución No 008430 de 1.993. Santafé de Bogotá (Colombia): Imprenta Nacional; 1993.

19. López MC, Quiróz DA, Pinilla AE. Diagnóstico de amebiasis intestinal y extraintestinal. Acta Med Colomb 2008; 33: 75-83.

20. WHO. Amoebiasis. Wkly Epidemiol Rec 1997; 72: 97-9.

21. Fotedar R, Stark D, Beebe N, Marriott D, Ellis J, Harkness J. Laboratory diagnostic techniques for Entamoeba species. Clin Microbiol Re 2007 ; 20: 511-32.

22. Stanley SL Jr. Amoebiasis. Lancet 2003; 361: 1025-34.

23. Haque R, Faruque ASG, Hahn P, Lyerly DM, Petri WA 
Jr. Entamoeba histolytica and Entamoeba dispar infection in children in Bangladesh. J Infect Dis 1997; 175: 734-6.

24. Haque R, Ali IKM, Sack RB, Farr BM, Ramakrishnan G, Petri WA Jr. Amebiasis and mucosal IgA antibody against the Entamoeba histolytica adherence lectin in Bangladeshi children. J Infect Dis 2001; 183: 1787-93.

25. Verweij JJ, Oostvogel F, Brienen EAT, Nang-Beifubah A, Ziem J, Polderman AM. Short communication: Prevalence of Entamoeba histolytica and Entamoeba dispar in northern Ghana. Trop Med Int H 2003; 8: 1153-6.

26. Visser LG, Verweij JJ, Esbroeck MV, Edeling WM, Clerinx J, Polderman AM. Diagnostic methods for differentiation of Entamoeba histolytica and Entamoeba dispar in carriers: Performance and clinical implications in a non-endemics setting. Intern J Med Microbiol 2006; 296: 397-403.

27. Furrows SJ, Moody AH, Chiodini PL. Comparison of PCR and antigen detection methods for diagnosis of Entamoeba histolytica infection. J Clin Pathol 2004; 57: 1264-6.

28. Solaymani-Mohammadi S, Rezaian M, Babaei Z,
Rajabpour A, Meamar AR, Pourbabai AA, et al. Comparison of stool antigen kit and PCR for diagnosis of Entamoeba histolytica and Entamoeba dispar infections in asymptomatic cyst passers in Iran. J Clin Microbiol 2006; 44: 2258-61.

29. Gonin P, Trudel L. Detection and differention of Entamoeba histolytica and Entamoeba dispar isolates in clinical samples by PCR and enzyme-linked inmunosorbent assay. J Clin Microbiol 2003; 41: 237-41.

30. Da Silva AJ, Bornay-Llinares FJ, Moura NS, Slemenda SB, Tutle JL, Pieniazek NJ. Fast and reliable extraction of protozoan parasite DNA from fecal specimens. Mol Diag 1999; 4: 57-64.

31. Pinilla AE, López MC, Viasus DF. Historia del protozoo Entamoeba histolytica. Rev Med Chile 2008; 136: 118-24.

32. Pritt BS, Clark CG Amebiasis. Mayo Clin Proc 2008; 83: 1154-60.

33. Nazemalhosseini Mojarad E, Nochi Z, Sahebekhtiari N, Rostami Nejad M, Dabiri H, Zali MR, et al. Discrimination of Entamoeba moshkovskii in patients with gastrointestinal disorders by single-round PCR. Jpn J Infect Dis 2010; 63: 136-8. 